\title{
Article \\ Enhancement of Antioxidant Activity and Bioactive Compounds in Eggplants Using Postharvest LEDs Irradiation
}

\author{
Amnat Jarerat ${ }^{1} \mathbb{1}$, Chairat Techavuthiporn ${ }^{2}$, Chanthana Chanchomsuek ${ }^{3}$ and Hataitip Nimitkeatkai ${ }^{3, *}$ \\ 1 Food Technology Program, Kanchanaburi Campus, Mahidol University, Saiyok, \\ Kanchanaburi 71150, Thailand; amnat.jar@mahidol.ac.th \\ 2 School of Industrial Education and Technology, King Mongkut's Institute of Technology Ladkrabang, \\ Ladkrabang, Bangkok 10520, Thailand; chairat.tec@gmail.com \\ 3 School of Agriculture and Natural Resources, University of Phayao, Muang, Phayao City 56000, Thailand; \\ chanthana.ch@up.ac.th \\ * Correspondence: hataitip.ni@up.ac.th; Tel.: +66-98-591-4459
}

Citation: Jarerat, A.; Techavuthiporn, C.; Chanchomsuek, C.; Nimitkeatkai, $\mathrm{H}$. Enhancement of Antioxidant Activity and Bioactive Compounds in Eggplants Using Postharvest LEDs Irradiation. Horticulturae 2022, 8, 134. https://doi.org/10.3390/ horticulturae 8020134

\section{Academic Editor: Hidemi Izumi}

Received: 29 December 2021

Accepted: 29 January 2022

Published: 2 February 2022

Publisher's Note: MDPI stays neutral with regard to jurisdictional claims in published maps and institutional affiliations.

Copyright: (C) 2022 by the authors. Licensee MDPI, Basel, Switzerland. This article is an open access article distributed under the terms and conditions of the Creative Commons Attribution (CC BY) license (https:// creativecommons.org/licenses/by/ $4.0 /)$.

\begin{abstract}
Eggplant (Solanum melongena L.), one of the major vegetable crops, is recognized for its availability of numerous bioactive compounds and antioxidant activity. The accumulation of these compounds in plant tissues can be increased by exogenous stimuli, including light exposure. This study aimed at enhancing the antioxidant activity and bioactive compounds of eggplant using lightemitting diode (LEDs) irradiation after harvest. For this purpose, eggplant fruits were irradiated under LEDs at different wavelengths, including red $(650-660 \mathrm{~nm})$, blue $(450-460 \mathrm{~nm})$, or the combination of red and blue (red + blue) LEDs, for $48 \mathrm{~h}$. The results indicated that red + blue LED exposure during postharvest significantly $(p<0.05)$ elevated the accumulation of bioactive compounds and antioxidant activity. The accumulation of major phenolic compounds, chlorogenic acid (58.59 mg/100 g FW), and gallic acid (14.25 mg/100 g FW) in the eggplant fruits was increased significantly under red + blue irradiation when compared with the control (under dark condition). The total phenolic (821.86 mg GAE/100 g FW) and the total flavonoid (595.98 mg CE/100 g FW) contents were shown to have a considerably high accumulation in the peels of eggplant after irradiation under red + blue LEDs, whereas the total carotenoid content was relatively high in the flesh of eggplant fruits. Consequently, red + blue LED irradiation can be considered as a convenient tool used for the postharvest of eggplant, with a positive effect in the increasing of important secondary metabolites. The obtained eggplant fruits proved to be a promising source of bioactive and antioxidant compounds for functional food production.
\end{abstract}

Keywords: antioxidant activity; bioactive compounds; chlorogenic acid; eggplant; light-emitting diodes (LEDs)

\section{Introduction}

Solanum melongena L., commonly known as eggplant, varies significantly in color, size, and form, depending on the specific variety [1]. Even though eggplant is commonly thought of as a vegetable, it is botanically classified as a fruit. The world production of eggplant is around 55.2 million tons [2]. It plays an important role as a food crop in many countries and is most widespread in Asia, North African, and Southern European cuisines. One of the most popular cultivars of eggplant in Japan today is a variety of "Shikon Sendai Naga", a bluish-purple pericarp with an elongated shape, and it is perfect for making pickles, served as a side dish [3].

For its high phenolic content, eggplant is considered to be one of the greatest vegetables in terms of oxygen radical absorbance capacity [4]. Aside from its antioxidant activity, related polyphenols and anthocyanins also demonstrate various effective biological activities, including anti-inflammatory, antimutagenic, and antiproliferative activities [5]. It has been reported that chlorogenic acid (5-O-caffeoylquinic acid) is the main component 
and represents 50-96\% of all phenolic compounds in eggplant [6]. However, a significant decrease of six-fold in the level of chlorogenic acid was observed in the first week of storage. Therefore, producing eggplant, particularly for higher levels of antioxidant and bioactive compounds, is an attempt to increase dietary antioxidant and health benefit intake.

Light can influence biological processes, whereby photo-stress can activate defense systems, resulting in an increase in the accumulation of phenylpropanoids, such as phenolic acids and flavonoids [7]. Generally, photoreceptors that intercept visible wavebands, including phytochromes, cryptochromes, and phototropins, have a synergistic influence on plant development [8]. Various light wavelengths have different effects on plant physiology and secondary metabolic compounds. Red light is considered to be essential for the photosynthetic apparatus and alters plant morphology through a response involving the action of phytochromes [8]. Blue light, conversely, mediated mostly by cryptochromes and phototropins, stimulates the biosynthesis of secondary metabolites that have photoprotective functions, such as carotenoid and anthocyanin [8]. This explains the selective use of light-emitting diodes (LEDs), which produce minimal longwave radiation that lacks external heat, unlike fluorescent or incandescent light [9]. Currently, LEDs have frequently been applied as a light source, emitting near infrared (NIR) radiation for indoor plant growth [8]. Irradiation with LEDs of different wavelengths has been studied for color development and the accumulation of bioactive compounds during the growth of several fruits and vegetables [7,8].

The effects of light quality and quantity are versatile and can lead to obtaining a variety of results. The response highly depends on the plant species, genotype, and growing condition. Blue and red LED treatments, for example, could improve the growth of different cultivars and microgreens, while also increasing the content of phenolic compounds, which are valuable phytochemicals. However, this depends on the pigmentation of the cultivar/species. The green cultivars such as broccoli sprouts are the most stimulated by a higher proportion of red light, while the red cultivars react the most to higher ratios of blue light [10]. The nutritional content of different sprouts (radish, soybean, mung bean, and pumpkin) grown under different light conditions (red, blue, and white light) depends on the dark or specific spectral wavelength used for their growth [11]. However, an increase in polyphenols was induced only in soybeans and only by red light. For the results during postharvest storage, irradiation with different light spectra has been studied in broccoli [12], tomato [13], cherry tomato [9], and apple [7]. Postharvest blue-light irradiation appears to enhance color and nutrition quality of red apples [7] and strawberry [14]. Red LEDs irradiation positively influence metabolic processes and contribute to a higher content of health-promoting substances in tomatoes [13].

The combination of red and blue LED light is one of the most efficient light sources for plant growth and development, as well as improving the quality of plant nutrition [15]. According to a previous report, red and blue (1:1) LEDs increased the flavonoid and ferricreducing antioxidant potential (FRAP) during tomato fruit development [15]. Moreover, red $(70 \%)$ and blue (30\%) LED light enhances the antioxidant capacity in lemon balm plants [16].

Despite the fact that there have been consistent studies on plants grown under LED lighting, up to the best of our knowledge, the effect of different LED wavelengths on the postharvest of eggplants has not been studied and reported. In this work, the effect of red, blue, or the combination of red and blue (red + blue) LEDs irradiation during postharvest to increase antioxidant activity and bioactive compounds such as carotenoid, flavonoid, anthocyanin, and chlorogenic acid contents of eggplant fruits was elucidated and demonstrated. It is recognized that the phytochemical compounds of fruits vary between parts of the same fruit [17]. In addition to the tailored changes in fruit quality under different LEDs lights, variations in the effect of LEDs light on the phytochemical compounds of the fruit components should be considered. Thus, the investigation was also extended to measure the antioxidant activity and bioactive compounds accumulated in the peel and flesh components of eggplants. 


\section{Materials and Methods}

\subsection{Plant Materials and LEDs Irradiation}

The fresh fruits of the Japanese eggplant (Solanum melongena L.) variety, of a bluish purple with an elongated shape, named "Shikon Sendai Naga" [3], at commercial maturity with an intermediate size (fruit length of 8-10 cm, weight 17-22 g) were manually harvested after $30 \pm 5$ days of anthesis by Hsu Chuan Foods Co., Ltd. (Chiang Rai, Thailand). Eggplants were transported to our laboratory by a temperature controlled vehicle within $1 \mathrm{~h}$. After selection, having being free of defects and diseases, eggplants were cleaned in circulated tap water and dried at room temperature. The eggplants were sampled on harvesting day, and they were used as an initial condition prior to exposing the fruit samples to darkness or LEDs irradiance.

To investigate the effect of LED irradiation, 30 eggplants per treatment were exposed under continuous red (650-660 nm), blue (450-460 nm), and red + blue (red 70\%, blue $30 \%$ ) LED light (Growlab Agritech Co., Ltd., Bangkok, Thailand) for 2 days in a controlled room temperature at $30 \pm 5{ }^{\circ} \mathrm{C}$, and $70 \%$ relative humidity $(\mathrm{RH})$. Lighting array of LEDs was $30 \mathrm{~cm}$ distance above the eggplant samples. The light intensity was maintained to $55 \mu \mathrm{mol}$ photons $/ \mathrm{m}^{2} / \mathrm{s}$, measured with a LI-COR Quantum meter (Li-Cor Inc., Lincoln, NE, USA). The control was stored in darkness in the same conditions. Samples were collected by separating the peel and flesh in strips of uniform thickness before further analysis.

\subsection{Firmness Measurement}

Eggplant firmness of 10 randomly selected fruits per treatment was measured by the TA-XT plus texture analyzer with a $\mathrm{p} / 2$ probe. Penetration tests were conducted with $\mathrm{p} / 2$-cylinder probe, penetrating in $6 \mathrm{~mm}$. The loading rate was $1 \mathrm{~mm} / \mathrm{s}$. The firmness was determined to be the mean of the maximum force (newton, $\mathrm{N}$ ).

\subsection{Color Determination}

Ten eggplants per treatment were randomly selected and measured for surface color by the $L^{*} a^{*} b^{*}$ system using a colorimeter (Minolta, Japan). Color components $L^{*}$, $a^{*}$, and $b^{*}$ were measured on three random points on the surface of eggplant fruits and reported as $L^{*}$ (lightness component) and the other two chromatic components, $a^{*}$ (from green to red) and $b^{*}$ (from blue to yellow). Hue angle $\left(\mathrm{h}^{\circ}\right)$ was calculated $\mathrm{as} \mathrm{h}^{\circ}=\tan ^{-1}\left(b^{*} / a^{*}\right)$ when $a^{*}$ and $b^{*}>0$.

\subsection{Carotenoid Content Analysis}

Carotenoid content of flesh and peel tissues was determined according to Davies et al. [18] with some modifications. One gram of sample was homogenized and extracted with $10 \mathrm{~mL}$ ethanol. Then, the extract sample was sonicated for $15 \mathrm{~min}$ and centrifuged at $10,000 \times g$ for $10 \mathrm{~min}$. The absorbance of supernatant was measured using an Evolution $201 \mathrm{UV}$-Vis spectrophotometer (Thermo Scientific, Madison, WI, USA) at $450 \mathrm{~nm}$. Total carotenoid content was evaluated using a standard curve of $\beta$-carotene and expressed as milligrams per gram extracts of $\beta$-carotene equivalents.

\subsection{Anthocyanin Content Analysis}

Peel tissues $(1 \mathrm{~g})$ was homogenized and extracted with $15 \mathrm{~mL} \mathrm{HCl}$-methanol $(0.15 \%$ $\mathrm{HCl}: 95 \%$ methanol $=15: 85)$ for $4 \mathrm{~h}$. The extract was centrifuged at 10,000 $\mathrm{g}$ for $20 \mathrm{~min}$ and the supernatant was measured for absorbance at 530,620, and $650 \mathrm{~nm}$. The anthocyanin content was based on the formula: $\Delta A / \mathrm{mL}=\left(A_{530}-A_{620}\right)-0.1\left(A_{650}-A_{620}\right)$ [19]. The anthocyanin content was expressed as $\Delta A / 100 \mathrm{~g}$ fresh weight (FW).

\subsection{Total Phenolic Content Analysis}

Eggplant samples were selected and peeled to separate the peel and flesh. Total phenolic content was analyzed using the method of Ketsa and Atantee [20]. Fresh flesh or peel (3 g) was homogenized in $25 \mathrm{~mL}$ of $80 \%$ methanol and centrifuged at $10,000 \times g$ for 
20 min at $4{ }^{\circ} \mathrm{C}$. The obtained supernatant was used to analyze the bioactive compounds and antioxidant activity. The reaction was started when $1 \mathrm{~mL}$ of supernatant was mixed with Folin-Ciocalteu reagent solution and $2 \mathrm{~mL}$ of saturated $\mathrm{Na}_{2} \mathrm{CO}_{3}$. The mixture was then incubated in the dark at room temperature for $60 \mathrm{~min}$. Total phenolic content was determined by measuring the absorbance at $765 \mathrm{~nm}$ and evaluated using a standard curve of gallic acid. The contents were expressed as milligrams of gallic acid equivalent per $100 \mathrm{~g}$ fresh weight (mg GAE/100 g FW).

\subsection{Total Flavonoid Content Analysis}

Total flavonoid content was adapted from the method of Youryon and Supapvanich [21] with slight modifications. The reaction was started when $0.5 \mathrm{~mL}$ of supernatant was added into a mixture of $1.25 \mathrm{~mL}$ of distilled water and $75 \mu \mathrm{L}$ of $0.5 \% \mathrm{NaNO}_{2}$. After being left for $6 \mathrm{~min}, 150 \mu \mathrm{L}$ of $10 \% \mathrm{AlCl}_{3} \cdot 6 \mathrm{H}_{2} \mathrm{O}$ and $0.5 \mathrm{~mL}$ of $1 \mathrm{M} \mathrm{NaOH}$ were added to the mixture. Total flavonoids content was determined by measuring the absorbance at $510 \mathrm{~nm}$. The data were expressed as milligrams of catechin equivalent per $100 \mathrm{~g}$ fresh weight (mg CE/100 $\mathrm{g}$ FW).

\subsection{Determination of Antioxidant Activity by DPPH and FRAP Assays}

The antioxidant activity was determined using a DPPH (2,2-diphenyl-2-picrylhydrazyl) radical scavenging assay according to the method of Brand-Williams et al. [22], with slight modifications. The supernatant was obtained from the same method of total phenolic measurement. The supernatant $(150 \mu \mathrm{L})$ was added to $2850 \mu \mathrm{L}$ DPPH in methanol. The reaction mixture was mixed and allowed to stand in the dark for 60 min at room temperature. The absorbance of the solution was measured at $515 \mathrm{~nm}$ using an Evolution $201 \mathrm{UV}-\mathrm{Vis}$ spectrophotometer. The percentage of inhibition assessed as antioxidant activity was calculated against blank:

$$
\text { DPPH inhibition }(\%)=[(\text { A blank }- \text { A sample }) / \text { A blank }] \times 100
$$

where A blank is the absorbance of the control reaction (containing all reagents except the test sample) and A sample is the absorbance of the reaction mixture.

The FRAP assay was done according to Thaipong et al. [23] with some modifications. The working solution was freshly prepared by mixing $25 \mathrm{~mL}$ of $300 \mathrm{mM}$ acetate buffer $(3.1 \mathrm{~g}$ $\mathrm{C}_{2} \mathrm{H}_{3} \mathrm{NaO}_{2} \cdot 3 \mathrm{H}_{2} \mathrm{O}$ and $16 \mathrm{~mL} \mathrm{C}_{2} \mathrm{H}_{4} \mathrm{O}_{2}$ ), pH 3.6, $2.5 \mathrm{~mL}$ of $10 \mathrm{mM}$ TPTZ (2,4,6-tripyridyl-striazine) solution, and $2.5 \mathrm{~mL}$ of $20 \mathrm{mM} \mathrm{FeCl}_{3} \cdot 6 \mathrm{H}_{2} \mathrm{O}$, and was then warmed at $37^{\circ} \mathrm{C}$. The supernatant of eggplant extracts $(150 \mu \mathrm{L})$ was added to $2850 \mu \mathrm{L}$ of the FRAP solution and allowed to react for $30 \mathrm{~min}$ in dark conditions. The absorbance of the color product (ferrous tripyridyltrizine complex) was measured at $593 \mathrm{~nm}$. The standard curve was linear between $\mathrm{FeSO}_{4}$ and FRAP solution. Results are expressed in $\mu \mathrm{mol} \mathrm{Fe}(\mathrm{II}) / 100 \mathrm{~g}$ fresh weight.

\subsection{HPLC Analysis of Gallic and Chlorogenic Acids}

The quantification of gallic acid and chlorogenic acid was carried out using a RP-HPLC (Jasco, Japan) at 280 and $325 \mathrm{~nm}$, respectively, with an external standard of authentic gallic and chlorogenic acids. A binary mobile phase gradient of methanol in $0.01 \%$ phosphoric acid was used, according to Mennella et al. [24] with minor modifications. The gradient program of the mobile phase at $0-15 \mathrm{~min}$, a linear increase from 5 to $25 \%$ methanol; 15-28 min, linear increase from 25 to 50\% methanol; 28-30 min, linear increase from 50 to 100\% methanol; 30-32 min, 100\% methanol; 32-36 min, linear decrease from 100 to 5\% methanol; $36-43 \mathrm{~min}, 5 \%$ methanol. The flow rate was $0.8 \mathrm{~mL} / \mathrm{min}$.

\subsection{Statistical Analysis}

The experiments were conducted using a completely randomized design (CRD). An analysis of variance (ANOVA) to evaluate treatment effects was performed using Duncan's multiple range test $(p<0.05)$ by SPSS software program version 18 . The data were presented as the mean values \pm SD. Except for the analysis of firmness and surface 
color of eggplant fruits $(n=10)$, all data are expressed as means and standard deviation (SD) $(n=3)$.

\section{Results}

\subsection{Firmness and Surface Colour of Eggplants}

Firmness of eggplant was evaluated after 2 days of storage period and was not significantly different between LED-illuminated and control fruit. The control and red + blue LEDs fruits had a tendency to be firmer than fruit treated with red and blue light (Table 1).

Table 1. Firmness and color $\left(L^{*}, a^{*}, b^{*}\right.$, hue angle) of eggplant after postharvest LEDs treatment.

\begin{tabular}{cccccc}
\hline LEDs Lights & Firmness (N) & $\boldsymbol{L}^{*}$ & $\boldsymbol{a}^{*}$ & $\boldsymbol{b}^{*}$ & $\mathbf{h}^{\circ}$ \\
\hline Initial & $975.15 \pm 57.31$ & $23.65 \pm 2.05$ & $3.98 \pm 0.96^{\mathrm{ab}}$ & $0.97 \pm 0.51$ & $0.23 \pm 0.11$ \\
Control & $995.29 \pm 35.84$ & $22.00 \pm 3.24$ & $4.42 \pm 0.54^{\mathrm{a}}$ & $0.87 \pm 0.79$ & $0.18 \pm 0.16$ \\
Red & $914.78 \pm 17.25$ & $21.91 \pm 0.60$ & $3.41 \pm 1.32^{\mathrm{abc}}$ & $0.46 \pm 0.44$ & $0.12 \pm 0.11$ \\
Blue & $927.42 \pm 47.55$ & $22.32 \pm 1.68$ & $2.41 \pm 0.94^{\mathrm{c}}$ & $0.89 \pm 0.57$ & $0.34 \pm 0.09$ \\
Red + blue & $998.25 \pm 8.90$ & $19.88 \pm 1.15$ & $2.57 \pm 0.87^{\mathrm{bc}}$ & $0.48 \pm 0.19$ & $0.18 \pm 0.04$ \\
\hline
\end{tabular}

${ }^{\mathrm{a}-\mathrm{c}}$ Means $\pm \mathrm{SD}$ in the column with different small superscript letters indicating significant difference at $p<0.05$ level $(n=10)$.

As shown in Table 1, there was no significant difference in $L^{*}$ between untreated and illuminated eggplants, although fruit treated with red + blue LED had the lowest lightness than other treatments.

The $a^{*}$ parameter of the initial, control (dark condition), and red LED light-treated eggplant fruits were comparable. The results also showed that after LEDs treatment under red and red + blue light, the fruits had comparable $a^{*}$ values. LED-treated eggplants under blue light had lower $a^{*}$ values, indicating a lighter redness when compared to the control and initial samples. In contrast, the parameters $b^{*}$ and $h^{\circ}$ showed no significant differences among the treatments.

\subsection{Total Carotenoid and Anthocyanin Contents of Eggplants}

As shown in Figure 1a, total carotenoid content in the fleshy part of eggplant was increased during the 2 days of storage. Red LED light increased carotenoid concentration more than red + blue lights, while blue LED light had no significant difference from the control one. When compared with the control, red + blue LEDs light significantly increased the total carotenoid content in the peel of eggplant. Peel and flesh of eggplant under red, blue, and red + blue LED irradiation had higher total carotenoid content than the initial condition.

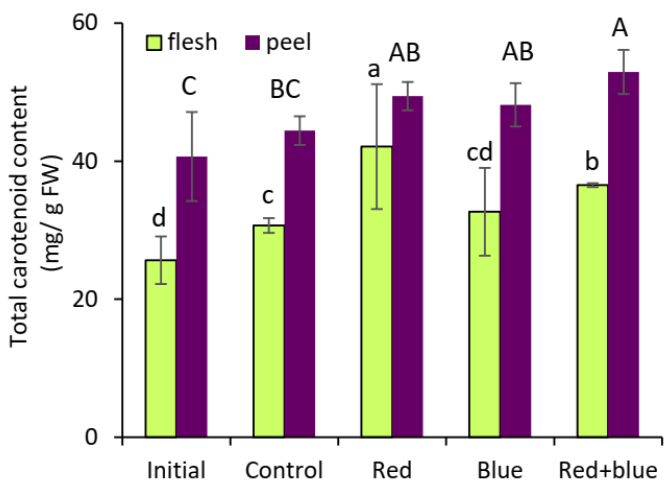

(a)

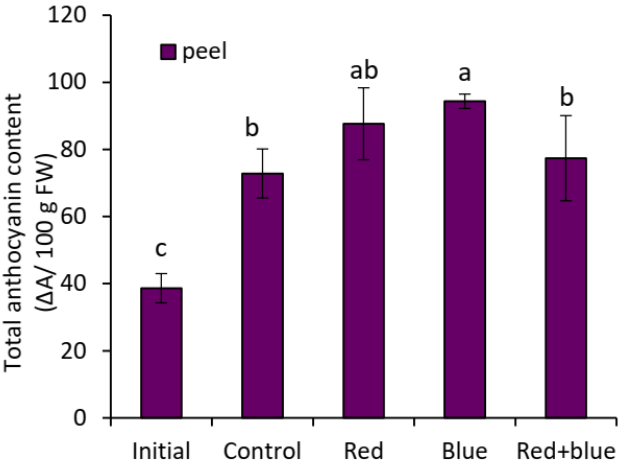

(b)

Figure 1. Effect of different LED lights on bioactive compounds: (a) total carotenoid content in flesh and peel of eggplants and (b) total anthocyanin content in peel of eggplants. Different letters a-d and A-C indicate statistically significant differences $(p<0.05)$ according to Duncan's multiple range test. Error bars show means $\pm \mathrm{SD}(n=3)$. 
An increase in total anthocyanin content of the peel was observed in eggplants during 2 days in storage, and LED treatment with blue and red lights increased the anthocyanin content higher than that of the control and red + blue LEDs treatment. There was no significant difference between the red + blue light and control in the accumulation of anthocyanin content (Figure $1 \mathrm{~b}$ ).

\subsection{Total Phenolic and Flavonoid Contents of Eggplants}

The total phenolic content of eggplants exposed under red, blue, and red + blue lights was increased after 2 days in storage from the initial day. LED treatment, especially red + blue light, increased total phenolic content in eggplant, both in the flesh and peel (Figure 2a). For the results of eggplant peel, red + blue LEDs light exhibited the highest total phenolic content. On the other hand, there was no significant difference in the total phenolic content of the peel when exposed under LEDs lights.

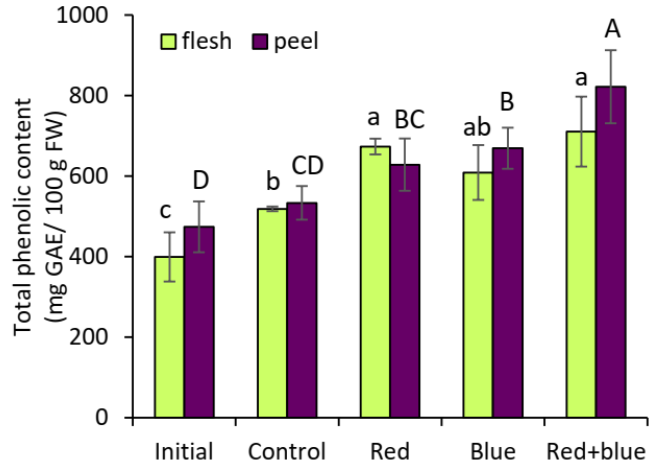

(a)

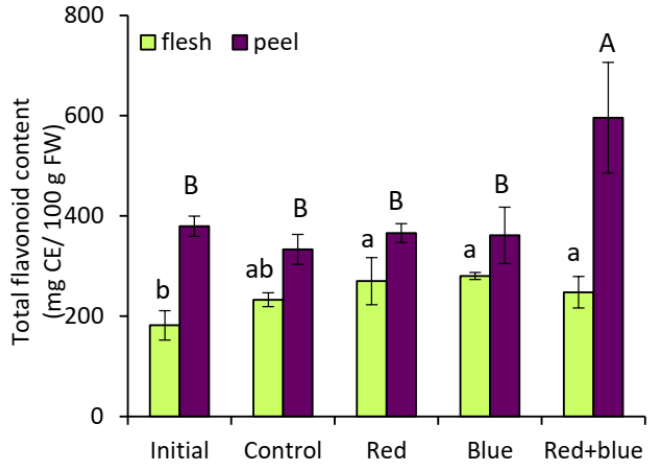

(b)

Figure 2. Effect of different LED lights on bioactive compounds: (a) total phenolic and (b) total flavonoid contents of eggplants. Different letters $\mathrm{a}-\mathrm{c}$ and A-D indicate statistically significant differences $(p<0.05)$, according to Duncan's multiple range test of the flesh and peel, respectively. Error bars show means $\pm \mathrm{SD}(n=3)$.

The total flavonoid content of eggplant showed no significant difference between the initial day and control treatments $(p>0.05)$. On the other hand, the peel of red + blue LED light treated samples significantly enhanced total flavonoids to the highest level, while the flesh part showed no significant difference between LED and control treatments (Figure 2b).

\subsection{Antioxidant Activity by DPPH and FRAP Assays of Eggplants}

Without LEDs irradiation, we observed a decrease in the DPPH inhibition of eggplant peel during storage for 2 days in the dark condition (control) (Figure 3a). It was found that red and red + blue lights resulted in a significant increase in the DDPH inhibition of eggplant flesh. There was a significant increase in the DPPH free-radical scavenging capacity in LED-treated eggplant peel, especially for red + blue LEDs. As shown in Figure $3 b$, the FRAP assay also showed the same tendency as the DPPH assay.

\subsection{Gallic and Chlorogenic Acid Contents of Eggplants}

The contents of the predominant phenolic compounds, gallic acid and chlorogenic acid, accumulated in flesh and peel were analyzed (Table 2). Red and blue LEDs increased the gallic acid content in the flesh of eggplant. However, only the gallic acid content in the peel of eggplant fruits was increased after the red + blue light irradiation when compared with the control. Both the flesh and peel of eggplant showed a significant accumulation of chlorogenic acid when exposed to red + blue LED light. 


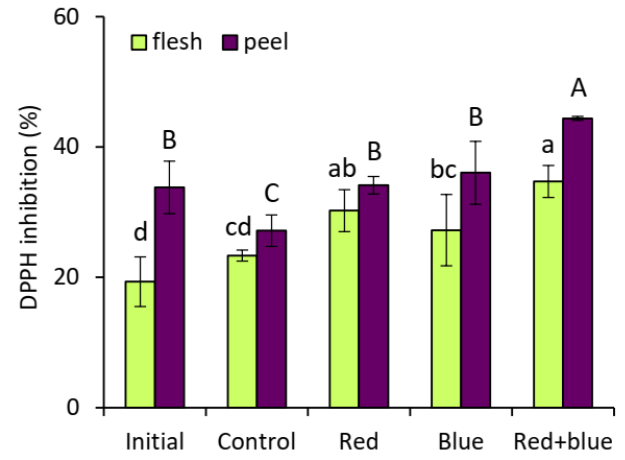

(a)

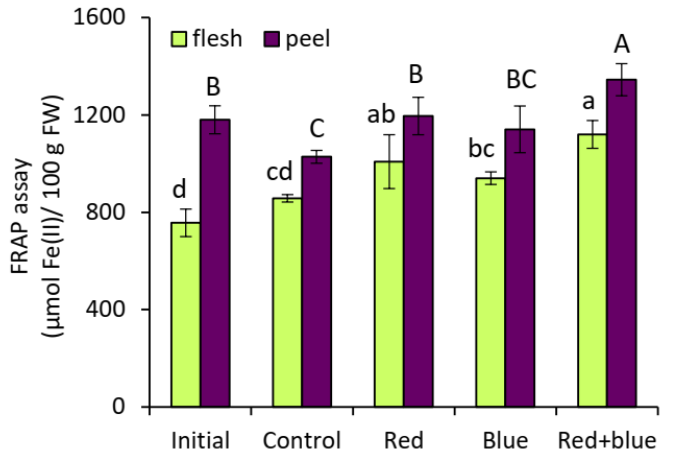

(b)

Figure 3. Effect of different LED lights on antioxidant activity: (a) DPPH inhibition and (b) FRAP assay of eggplants. Different letters a-d and A-C indicate statistically significant differences $(p<0.05)$ according to Duncan's multiple range test of flesh and peel, respectively. Error bars show means \pm SD $(n=3)$.

Table 2. Gallic and chlorogenic acid contents of eggplants after LED postharvest treatment.

\begin{tabular}{cccc}
\hline Plant Parts & LEDs Lights & $\begin{array}{c}\text { Gallic Acid } \\
\text { (mg/100 g FW) }\end{array}$ & $\begin{array}{c}\text { Chlorogenic Acid } \\
\text { (mg/100 g FW) }\end{array}$ \\
\hline \multirow{3}{*}{ Flesh } & Initial & $7.03 \pm 0.51^{\mathrm{c}}$ & $16.93 \pm 3.23^{\mathrm{b}}$ \\
& Control & $7.99 \pm 0.67^{\mathrm{bc}}$ & $16.05 \pm 1.81^{\mathrm{b}}$ \\
& Red & $9.72 \pm 0.70^{\mathrm{a}}$ & $14.24 \pm 0.24^{\mathrm{b}}$ \\
& Blue & $8.98 \pm 0.93^{\mathrm{ab}}$ & $17.27 \pm 2.91^{\mathrm{b}}$ \\
& Red + blue & $7.97 \pm 0.95^{\mathrm{bc}}$ & $58.59 \pm 17.53^{\mathrm{a}}$ \\
\hline \multirow{3}{*}{ Peel } & Initial & $11.22 \pm 1.21^{\mathrm{ab}}$ & $21.92 \pm 0.81^{\mathrm{b}}$ \\
& Control & $6.56 \pm 0.46^{\mathrm{c}}$ & $15.16 \pm 1.71^{\mathrm{c}}$ \\
& Red & $8.36 \pm 0.66^{\mathrm{bc}}$ & $22.10 \pm 3.37^{\mathrm{b}}$ \\
& Blue & $6.53 \pm 0.40^{\mathrm{c}}$ & $16.21 \pm 1.16^{\mathrm{c}}$ \\
& Red + blue & $14.25 \pm 3.94^{\mathrm{a}}$ & $35.02 \pm 3.12^{\mathrm{a}}$
\end{tabular}

$\overline{\mathrm{a}-\mathrm{c}}$ Means \pm SD in the column with different small superscript letters indicate significant difference at $p<0.05$ level $(n=3)$.

\section{Discussion}

The postharvest quality of fruit and vegetables is influenced by tissue turgidity, which is primarily measured by the dehydration during storage [12]. In our study, LED light treatment had no significant effect on eggplant firmness, although red and blue LEDs slightly decreased the fruit firmness (Table 1). Ngcobo et al. [9] also reported that LED light did not have a main effect on the activity of the enzymes involved in cell wall degradation in cherry tomato, which belong to the same genus as eggplant.

It has been reported that after harvest, the intensity, duration, and quality of light have a significant impact on phytochemical accumulation [13]. Light affects pigment metabolism, enhancing the color of various vegetables, such as tomatoes, broccoli, and other crops [9,25]. In present study, carotenoid content was greatly increased by irradiation with red LED light. Red + blue LEDs with 70\% red and 30\% blue also increased the concentration of total carotenoid more than blue light alone in the flesh of eggplant during postharvest (Figure 1a). The result of our study is in accordance with the findings of Ngcobo et al. [9], who found that red light affects the concentration or presence of carotenoids in the postharvest of red tomato tissues, and who also proposed that phytochrome, a photoreceptor response to red wavelength, appears to promote carotenoid biosynthesis in green mature tomato tissues. Samuolienè et al. [25] showed that red LED light apparently had a stronger effect than blue on the color-altering steps of baby leaf lettuce. In contrast, the highest carotenoid content was detected in broccoli stored under continuous postharvest white-blue LED [12]. 
Anthocyanins are red plant pigments that, among many other roles, protect plants from photo inhibition and photo damage by absorbing solar radiation [25]. In this study, blue LEDs enhanced the concentration of anthocyanin in eggplant peel. The effect of red light on anthocyanin accumulation was relatively low, but still showed a positive effect when compared to red + blue light (Figure 1b). It was reported that blue light regulates anthocyanin biosynthesis through the phytochrome system [25]. Anthocyanin synthesis is light-regulated, and the red leaf color appears on lettuce leaves in varying intensities and distributions. Blue light treatment improved total anthocyanin content by activating its related enzymes during the postharvest of strawberry [14]. Li et al. [26] also demonstrated the involvement of apple anthocyanin production through a blue-light photoreceptor cryptochrome.

The total phenolic content was related to the accumulation of phenolic compounds, including total anthocyanin content (Figure 1b), total flavonoid content (Figure 2b), gallic acid, and chlorogenic acid contents (Table 2). Our findings are in agreement with a previous study of Mannella et al. [24], who have observed the significantly correlation of chlorogenic acid content to the total phenolic amount in eggplants. In addition to the pigment of anthocyanin, it appeared that the eggplant peel also contained highly bioactive compounds, thus, increasing the antioxidant capacity. Our results indicated that the highest total phenolic content was correlated with a significant increase in the DPPH free-radical scavenging capacity and FRAP assay in the postharvest eggplant under red + blue irradiation. A previous study of various eggplant species revealed that total phenolic compounds and chlorogenic acid appear to have the main influence on antioxidant capacity [24]. For the results regarding plant pigment, light has been reported to affect pigment metabolism, enhancing the color of various vegetables, such as tomatoes, broccoli, and other crops [25]. The pigment groups of plants confer certain health benefits to humans, acting as powerful antioxidants.

Bioactive compounds, including phenolic acids and flavonoids, play an important role in scavenging free radicals and oxidants to protect cell damage [27]. In the present study, a significant increase in the level of chlorogenic acid was observed in red + blue LED-treated eggplant. The increase in bioactive compounds in red + blue LED-exposed eggplants is probably caused by the stimulation of genes, owing to the phenylpropanoid pathway, which is related to the biosynthesis of phenolic acids and flavonoid content in plants $[8,28]$. The other explanation for the higher antioxidant activity of plants exposed to blue LEDs is that the higher energy levels of short wavelengths (blue at $450-460 \mathrm{~nm}$ for example) stimulate oxidative stress, thus enhancing the scavenging of reactive oxygen species [16]. Park et al. [29] recently demonstrated that exposure to blue LED light can enhance the production of the majority of phenolic compounds, including gallate, quercetin, caffeate, and chlorogenic acid in Brassica juncea sprouts. The effect of red LEDs in combination with blue LEDs has been observed by Ahmadi et al. [16] in lemon balm, where red + blue lights maintained higher antioxidant and phenylalanine ammonialyase enzyme activities. One of the reasons for the high production of bioactive compounds and antioxidant activities is the presence of red and blue wavelengths in the light spectrum. The higher energy levels of blue wavelengths and the induction of oxidative stress due to the presence of red wavelengths, both of which exist in the spectrum of red + blue LED light [16].

Polyphenols with antioxidant activity, predominantly found in the peel, represent the fruit defense mechanism against external agents. The different parts of mandarin fruit are rigorously related to relevant species characteristics [17]. The results of eggplant showed that LEDs light stimulated the accumulation of bioactive compounds and antioxidant activity both in flesh and peel tissues. In addition, it was noticeable that the peel was rich in bioprotective compounds after being irradiated with red + blue LEDs. Whether LED irradiation stimulate phenolic compounds and flavonoid biosynthesis in eggplant fruits is still unclear at present, and needs further analysis.

Many previous studies have reported that blue light increases the production of phenolic compounds. However, the current and previous studies propose that the effect of different light sources and wavelengths on plant secondary metabolite accumulation varies 
depending on species, cell and tissue type, and plant organ. Further research is necessary to determine the specific intensity and duration of LED lighting that can be used to enhance the production of key substances.

\section{Conclusions}

We have demonstrated that LED irradiation revealed its effective use in the postharvest of eggplant fruits, in terms of increasing the accumulation of bioactive compounds, including total phenolic, total flavonoid, carotenoid, and anthocyanin contents, as well as antioxidant activity.

Anthocyanin content was increased under red $(650-660 \mathrm{~nm})$ and blue $(450-460 \mathrm{~nm})$ monochrome of LEDs irradiation. Carotenoid content, however, was higher when accumulated after $48 \mathrm{~h}$ using postharvest red LED irradiation. The accumulation of phenolic compounds that exhibited ferric ion-reducing antioxidant power (FRAP assay) and free radical-scavenging activity (DPPH inhibition) were increased by predominantly red + blue light in the eggplant fruits. Major individual phenolic compounds were determined as chlorogenic and gallic acids. Under predominantly red + blue irradiation, chlorogenic acid accumulation was relatively high (up to 2.3- and 3.7-fold, in peel and flesh, respectively) when compared to control treatment. Combinations of red and blue LEDs can be tailored to increase superior antioxidant activity and phenolic content in eggplant, as an effective and convenient tool for increasing the quality of postharvest eggplant fruits.

Author Contributions: Conceptualization, A.J. and H.N.; methodology, C.T., C.C. and H.N.; validation, A.J., C.T. and H.N.; formal analysis, C.C.; data curation, C.T. and H.N.; writing-original draft preparation, A.J., C.T. and H.N.; writing-review and editing, A.J. and H.N.; supervision, H.N.; funding acquisition, H.N. All authors have read and agreed to the published version of the manuscript.

Funding: This research was financial supported by Agricultural Research Development Agency (Public Organization) of Thailand [Grant Number: CRP6405031900].

Institutional Review Board Statement: Not applicable.

Informed Consent Statement: Not applicable.

Data Availability Statement: Data are contained within the article.

Acknowledgments: We wish to thank Hsu Chuan Foods Co., Ltd. (Chiang Rai, Thailand) for donating the plant materials used for experiments.

Conflicts of Interest: The authors declare no conflict of interest.

\section{References}

1. Shama, M.; Kaushik, P. Biochemical composition of eggplant fruits: A review. Appl. Sci. 2021, 11, 7078. [CrossRef]

2. FAO. Food and Agriculture Organization of United Nations: Crops. Available online: http://www.fao.org/faostat/en/\#data/QC (accessed on 28 December 2021).

3. Tsukagoshi, S.; Kuroda, K.; Hohjo, M.; Ikegami, F.; Kunisaki, N.; Hanamura, T.; Yamada, K.; Hagiwara, T. Evaluation of local eggplant cultivars in terms of the suitability as materials for "Yakuzen" dishes. Adv. Hort. Sci. 2014, 28, 105-110.

4. Luthria, D.L. A simplified UV spectral scan method for the estimation of phenolic acids and antioxidant capacity in eggplant pulp extracts. J. Funct. Foods 2012, 4, 238-242. [CrossRef]

5. Huang, W.Y.; Cai, Y.Z.; Zhang, Y.B. Natural phenolic compounds from medicinal herbs and dietary plants: Potential use for cancer prevention. Nutr. Cancer 2010, 62, 1-20. [CrossRef] [PubMed]

6. S Šilarova, P.; Boulekbache-Makhlouf, L.; Pellati, F.; Česlová, L. Monitoring of chlorogenic acid and antioxidant capacity of Solanum melongena L. (eggplant) under different heat and storage treatments. Antioxidants 2019, 8, 234. [CrossRef] [PubMed]

7. Kokalj, D.; Zlatić, E.; Cigić, B.; Kobav, M.B.; Vidrih, R. Postharvest flavonol and anthocyanin accumulation in three apple cultivars in response to blue-light-emitting diode light. Sci. Hort. 2019, 257, 108711. [CrossRef]

8. Landi, M.; Zivcak, M.; Sytar, O.; Brestic, M.; Allakhverdiev, S.I. Plasticity of photosynthetic processes and the accumulation of secondary metabolites in plants in response to monochromatic light environments: A review. BBA Bioenerg. 2020, $1861,148131$. [CrossRef] [PubMed]

9. Ngcobo, B.L.; Bertling, I.; Clulow, A.D. Post-harvest alterations in quality and health-related parameters of cherry tomatoes at different maturity stages following irradiation with red and blue LED lights. J. Hortic. Sci. Biotechnol. 2021, 96, 383-391. [CrossRef] 
10. Castillejo, N.; Martínez-Zamora, L.; Gómez, P.A.; Pennisi, G.; Crepaldi, A.; Fernández, J.A.; Orsini, F.; Artés-Hernández, F. Postharvest LED lighting: Effect of red, blue, and far red on quality of minimally processed broccoli sprouts. J. Sci. Food Agric. 2021, 101, 44-53. [CrossRef] [PubMed]

11. Mastropasqua, L.; Dipierro, N.; Paciolla, C. Effects of darkness and light spectra on nutrients and pigments in radish, soybean, muan bean and pumpkin sprouts. Antioxidants 2020, 9, 558. [CrossRef]

12. Hasperué, J.H.; Guardianelli, L.; Rodoni, L.M.; Chaves, A.R.; Martínez, G.A. Continuous white-blue LED light exposition delays postharvest senescence of broccoli. LWT-Food Sci. Technol. 2016, 65, 495-502. [CrossRef]

13. Panjai, L.; Noga, G.; Hunsche, M.; Fiebig, A. Optimal red light irradiation time to increase health-promoting compounds in tomato fruit postharvest. Sci. Hort. 2019, 251, 189-196. [CrossRef]

14. Xu, F.; Cao, S.; Shi, L.; Chen, W.; Su, X.; Yang, Z. Blue light irradiation affects anthocyanin content and enzyme activities involved in postharvest strawberry fruit. J. Agric. Food Chem. 2014, 62, 4778-4783. [CrossRef]

15. Xie, B.; Song, S.; Liu, H.; Sun, G.; Chen, R. Effects of light quality on the formation of tomato fruits. Adv. Biol. Sci. Res. 2016, 3 , $11-15$.

16. Ahmadi, T.; Shabani, L.; Sabzalian, M.R. LED light mediates phenolic accumulation and enhances antioxidant activity in Melissa officinalis L. under drought stress condition. Protoplasma 2020, 257, 1231-1242. [CrossRef]

17. Costanzo, G.; Iesce, M.R.; Naviglio, D.; Ciaravolo, M.; Vitale, E.; Arena, C. Comparative studies on different Citrus cultivars: A revaluation of waste mandarin components. Antioxidants 2020, 9, 517. [CrossRef]

18. Davies, B.H. Carotenoids. In Chemistry and Biochemistry of Plant Pigments; Academic Press: London, UK, 1976 ; pp. 38-165.

19. Zheng, X.; Tial, S. Effect of oxalic acid on control of postharvest browning of litchi fruit. Food Chem. 2006, 96, 519-523. [CrossRef]

20. Ketsa, S.; Atantee, S. Phenolics, lignin, peroxidase activity and increased firmness of damaged pericarp of mangosteen fruit after impact. Postharvest Biol. Technol. 1998, 14, 117-124. [CrossRef]

21. Youryon, P.; Supapvanich, S. Physicochemical quality and antioxidant changes in banana fruit during ripening. Agric. Nat. Resour. 2017, 51, 47-52.

22. Brand-Williams, W.; Cuvelier, M.E.; Berset, C. Use of free radical method to evaluate antioxidant activity. LTW-Food Sci. Technol. 1995, 28, 25-30. [CrossRef]

23. Thaipong, K.; Boonprakob, U.; Crosby, K.; Cisneros-Zevallos, L.; Byrne, D.H. Comparison of ABTS, DPPH, FRAP, and ORAC assays for antioxidant activity from guava fruit extracts. J. Food Compos. Anal. 2006, 19, 669-675. [CrossRef]

24. Mennella, G.; Scalzo, R.L.; Fibiani, M.; D'Alessandro, A.; Francese, G.; Toppino, L.; Acciarri, N.; Almeida, A.E. Chemical and bioactive quality traits during fruit ripening in eggplant (S. melongena L.) and allied species. J. Agric. Food Chem. 2012, 60, 11821-11831. [CrossRef] [PubMed]

25. Samuolienè, G.; Sirtautas, R.; Brazaitytè, A.; Duchovskis, P. LED lighting and seasonality effects antioxidant properties of baby leaf lettuce. Food Chem. 2012, 134, 1494-1499. [CrossRef] [PubMed]

26. Li, Y.Y.; Mao, K.; Zhao, C.; Zhao, X.Y.; Zhang, R.F.; Zhang, H.L.; Shu, H.R.; Hao, Y.J. Molecular cloning and functional analysis of a blue light receptor gene MdCRY2 from apple (Malus domestica). Plant Cell Rep. 2013, 32, 555-566. [CrossRef] [PubMed]

27. Piluzza, G.; Bullitta, S. Correlations between phenolic content and antioxidant properties in twenty-four plant species of traditional ethnoveterinary use in the Mediterranean area. Pharm. Biol. 2011, 49, 240-247. [CrossRef] [PubMed]

28. Park, W.T.; Yeo, S.K.; Park, J.S.; Kim, J.K.; Park, S.U. Influence of light-emitting diodes on phenylproponoid biosynthetic gene expression and phenylpropanoid accumulation in Agastache rugosa. Appl. Biol. Chem. 2020, 63, 25. [CrossRef]

29. Park, C.H.; Park, Y.E.; Yeo, H.Y.; Kim, J.K.; Park, S.U. Effects of light-emitting diodes on the accumulation of phenolic compounds and glucosinolates in Brassica juncea sprouts. Horticulturae 2020, 6, 77. [CrossRef] 